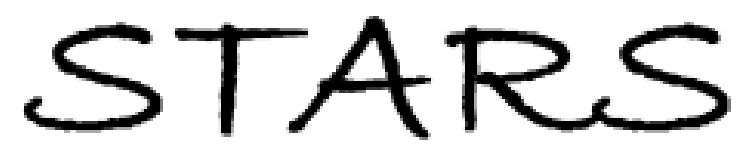

University of Central Florida

STARS

$1-1-2007$

\title{
Band gap energy modifications observed in trivalent In substituted nanocrystalline $\mathrm{SnO} 2$
}

C. Drake

University of Central Florida

S. Seal

University of Central Florida

Find similar works at: https://stars.library.ucf.edu/facultybib2000 University of Central Florida Libraries http://library.ucf.edu

This Article is brought to you for free and open access by the Faculty Bibliography at STARS. It has been accepted for inclusion in Faculty Bibliography 2000 s by an authorized administrator of STARS. For more information, please contact STARS@ucf.edu.

\section{Recommended Citation}

Drake, C. and Seal, S., "Band gap energy modifications observed in trivalent In substituted nanocrystalline Sn02" (2007). Faculty Bibliography 2000s. 7069.

https://stars.library.ucf.edu/facultybib2000/7069

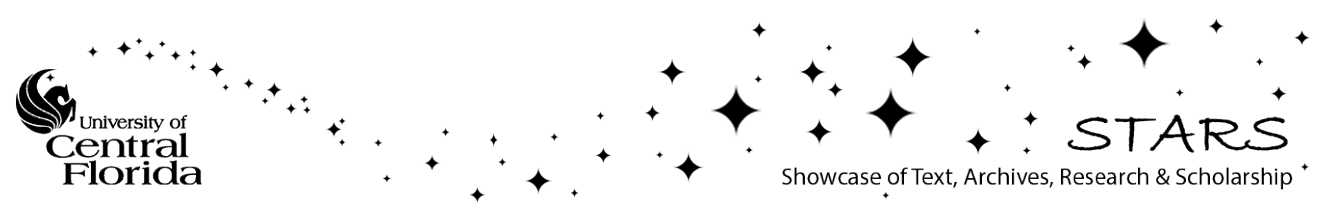




\section{Band gap energy modifications observed in trivalent In substituted nanocrystalline $\mathrm{SnO}_{2}$}

Cite as: Appl. Phys. Lett. 90, 233117 (2007); https://doi.org/10.1063/1.2746407

Submitted: 05 March 2007 . Accepted: 11 May 2007 . Published Online: 11 June 2007

C. Drake, and S. Seal

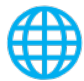

View Online

\section{ARTICLES YOU MAY BE INTERESTED IN}

Structural and optical properties of $\mathrm{Cu}$ doped $\mathrm{SnO}_{2}$ nanoparticles: An experimental and density functional study

Journal of Applied Physics 113, 233514 (2013); https://doi.org/10.1063/1.4811374

Atomic nitrogen doping and p-type conduction in $\mathrm{SnO}_{2}$

Applied Physics Letters 95, 222112 (2009); https://doi.org/10.1063/1.3258354

Enhancing the low temperature hydrogen sensitivity of nanocrystalline $\mathrm{SnO}_{2}$ as a function of trivalent dopants

Journal of Applied Physics 101, 104307 (2007); https://doi.org/10.1063/1.2732498

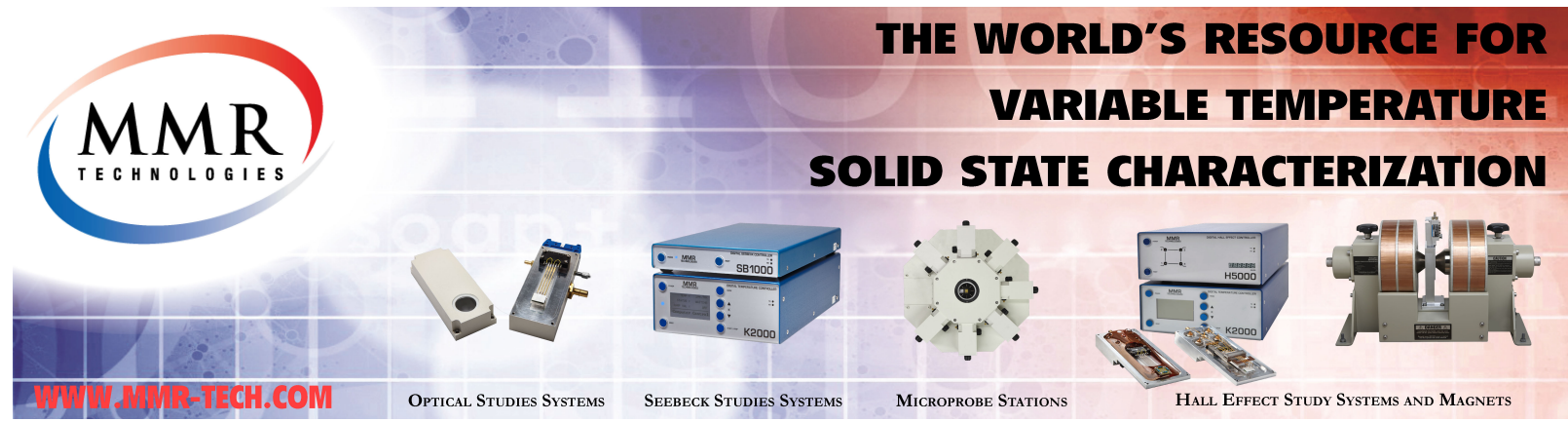




\title{
Band gap energy modifications observed in trivalent In substituted nanocrystalline $\mathrm{SnO}_{2}$
}

\author{
C. Drake and S. Seal ${ }^{\text {a) }}$ \\ Surface Engineering and Nanotechnology Facility (SNF) Laboratory, University of Central Florida, \\ 4000 Central Florida Blvd., Orlando, Florida 32826; Advanced Materials Processing and Analysis Center, \\ University of Central Florida, 4000 Central Florida Blvd., Orlando, Florida 32826; \\ Mechanical Materials and Aerospace Engineering, University of Central Florida, Eng 1, Room No. 381, \\ 4000 Central Florida Blvd., Orlando, Florida 32826; and Nanoscience and Technology Center, \\ University of Central Florida, 4000 Central Florida Blvd., Orlando, Florida 32826
}

(Received 5 March 2007; accepted 11 May 2007; published online 11 June 2007)

The effect of In doping concentration on the optical band gap of nano- $\mathrm{SnO}_{2}$ is investigated as a function of calcination temperature. Changes in the band gap explain the room temperature $\mathrm{H}_{2}$ gas sensing of doped nano- $\mathrm{SnO}_{2}$. The band gap was found to be lower than those reported for $\mathrm{SnO}_{2}$ $(3.6 \mathrm{eV})$ from 2.55 to $3.43 \mathrm{eV}$ and may be explained by the presence of nonequilibrium oxygen vacancies in the oxide lattice and band bending effects at the nanoscale. (c) 2007 American Institute of Physics. [DOI: 10.1063/1.2746407]

Nanocrystalline $\mathrm{SnO}_{2}$ is an important transparent material due to its potential use in many applications, including gas sensors. Doping of the $\mathrm{SnO}_{2}$ system has been a point of interest due to the ability to tailor its electrical and microstructural properties. ${ }^{1-6}$ In the area of sensors and other electronic applications, tailoring of the electronic structure in nanocrystalline materials has become pivotal. $^{7-9}$

$\mathrm{SnO}_{2}$ is a wide band gap semiconductor with a band gap at $3.6 \mathrm{eV}$ and higher at $300 \mathrm{~K} .^{10-15}$ The space charge layer control of nanostructures, including nano- $\mathrm{SnO}_{2}$, makes them particularly interesting since conduction can change drastically with expansion and contraction of the layer in the presence of different gases. ${ }^{16,17}$ The energy required for electrons or other charged species from adsorbed gas molecules to conduct through the material can be greatly impacted by the magnitude of the band gap and whether or not any energy level exists within the forbidden gap. This letter will focus on changes in the direct optical band gap of nano- $\mathrm{SnO}_{2}$ doped with trivalent In substitution that deviate from what is largely reported.

Indium doped $\mathrm{SnO}_{2}$ was prepared using a sol-gel method. ${ }^{17} \mathrm{~A}$ sol of tin isopropoxide in isopropanol (72 vol \%) and toluene (18 vol \%) and indium isopropoxide was prepared. A polymer, hydroxypropyl cellulose, was added to control the grain size during the gelling reaction. The gel is dried at $150{ }^{\circ} \mathrm{C}$ for $1 \mathrm{~h}$ in air. Powders were then calcined at $500,600,800$, and $1000{ }^{\circ} \mathrm{C}$ for $1 \mathrm{~h}$ in air. The subsequent drying and pyrolysis treatments of the coated polymer nanostructures then result in the decomposition of the polymer structure, leaving behind $\mathrm{In}-\mathrm{SnO}_{2}$ nanocrystallites. The following are the sol-gel reactions during the drying and pyrolysis procedures: ${ }^{17}$

(1) $\mathrm{Sn}\left(\mathrm{OC}_{3} \mathrm{H}_{7}\right)_{4}+4 \mathrm{H}_{2} \mathrm{O} \rightarrow \mathrm{In}-\mathrm{Sn}(\mathrm{OH})_{4}+4 \mathrm{C}_{3} \mathrm{H}_{7} \mathrm{OH}$ $\left.25{ }^{\circ} \mathrm{C}\right)$,

(at

${ }^{a)}$ Electronic mail: sseal@mail.ucf.edu
(2) $\mathrm{Sn}(\mathrm{OH})_{4} \rightarrow \mathrm{SnO}_{2}$ (amorphous) $+2 \mathrm{H}_{2} \mathrm{O}$ (at $150{ }^{\circ} \mathrm{C}$ ), and

(3) $\mathrm{SnO}_{2}$ (amorphous) $\rightarrow \mathrm{SnO}_{2}$ (crystalline) (at $400{ }^{\circ} \mathrm{C}$ ).

Structural verification of the $\mathrm{SnO}_{2}$ rutile (cassiterite) structure by $\mathrm{x}$-ray diffraction and high-resolution transmission electron microscopy (Fig. 1) is published elsewhere. ${ }^{18}$ Ultraviolet-visible (UV-Vis) measurements were carried out on a Cary 1 UV-Vis spectrophotometer from Varian, Inc. Doped $\mathrm{SnO}_{2}$ nanocrystalline powders were compressed and scanned in the range of 200 to $800 \mathrm{~nm}$ using a Labsphere integrating sphere.

The size of the $\mathrm{In}-\mathrm{SnO}_{2}$ nanoparticles based on calcination temperature and amount of In doping is shown in Table I. It is observed that the particles retain their nanocrystalline nature even at the higher calcination temperatures. It is also worth noting that the size of nanocrystalline $\mathrm{In}-\mathrm{SnO}_{2}$ at the lower calcination temperatures is nearly independent of the amount of doping.

For crystalline $\mathrm{SnO}_{2}$, optical transitions have been shown to be direct. ${ }^{19}$ The variation in the absorption coefficient as a function of photon energy for allowed direct transitions is given by

$$
\alpha=A\left(h \nu-E_{g}\right)^{1 / 2},
$$

where $\alpha$ is the absorption coefficient, $A$ is a constant, $h$ is Planck's constant, $\nu$ is the frequency, and $E_{g}$ is the band gap energy. The absorption coefficient $\alpha$ is obtained from Beer's law,

$$
I=I_{0} \exp (-\alpha x) .
$$

In the above equation, $x$ is the thickness of the measured sample. A plot of $\alpha^{2}$ versus photon energy was used to obtain the value of the direct band gap by extrapolating the linear portion of the curves to zero absorption.

The overall values obtained for all dopings and calcination temperatures are lower than the reported values for $\mathrm{SnO}_{2}$, usually reported around $3.6 \mathrm{eV}$. Plots, to obtain band gap values for $1 \%$ In doped samples, are shown in Fig. 2(a). The highest band gap value was obtained for the sample calcined at $500{ }^{\circ} \mathrm{C}$ at $3.1 \mathrm{eV}$. The band gap values decreased until a calcination temperature of $1000{ }^{\circ} \mathrm{C}$, where it slightly 

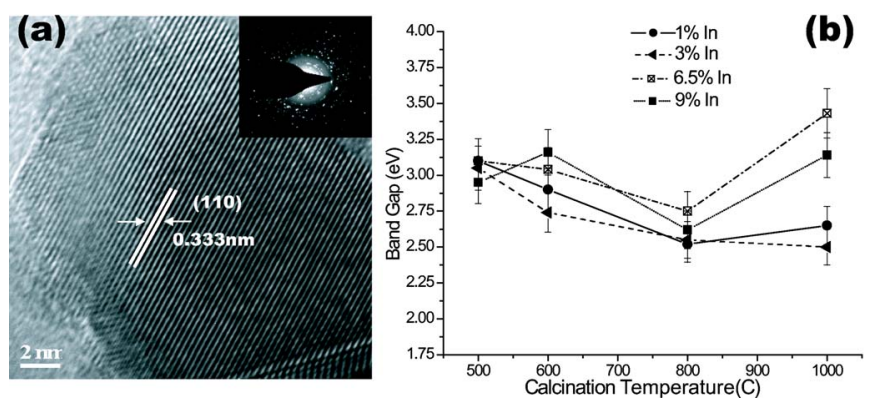

FIG. 1. (Color online) (a) High-resolution transmission electron microscopy of $6.5 \% \mathrm{In}-\mathrm{SnO}_{2}$ and (b) band gap changes as a function of calcination temperature for $\mathrm{In}-\mathrm{SnO}_{2}$.

increased from the $800{ }^{\circ} \mathrm{C}$ sample, $2.52-2.65 \mathrm{eV}$. For the $3 \%$ doped samples [Fig. 2(b)] the same trend is followed as that of the $1 \%$ doped samples. The highest value for the $3 \%$ samples is for the one calcined at $500{ }^{\circ} \mathrm{C}$ with a value of $3.05 \mathrm{eV}$. The values again decrease until a calcination temperature of $1000{ }^{\circ} \mathrm{C}$, where the value slightly increases to $2.5 \mathrm{eV}$. For the $6.5 \%$ doped samples, a similar trend is noted, with a decrease in the band gap values with increasing calcination temperature until $1000{ }^{\circ} \mathrm{C}$, where the value increases [Fig. 2(c)]. Unlike the $1 \%$ and $3 \%$ doped samples, the highest value of the band gap is obtained at a calcination temperature of $1000{ }^{\circ} \mathrm{C}$ at $3.43 \mathrm{eV}$. For the $9 \%$ doped samples, the trend is different from the other dopings [Fig. 2(d)]. Between 500 and $600{ }^{\circ} \mathrm{C}$, the band gap decreases (from 3.14 to $2.62 \mathrm{eV}$ ) but then increases at $800{ }^{\circ} \mathrm{C}$ to $3.16 \mathrm{eV}$. At $1000{ }^{\circ} \mathrm{C}$ the band gap decreases.

In the case of In doped samples, the band gap drops with initial increase in doping amount $(1 \%-3 \%)$ and then increases at $6.5 \%$ [Fig. 1(b)]. A similar trend was reported in Co doped $\mathrm{SnO}_{2}$. ${ }^{20}$

Full doping of $\mathrm{SnO}_{2}$ with indium will lead to substitution of $\mathrm{In}^{3+}$ onto a $\mathrm{Sn}^{4+}$ site and the creation of oxygen vacancies to retain charge neutrality within the cassiterite structure. In the Kroger-Vink notation, charge modification upon doping occurs as

$$
\begin{aligned}
& \mathrm{O}_{0}^{x} \rightarrow \frac{1}{2} \mathrm{O}_{2(g)}+V_{\mathrm{O}}^{00}+2 e^{-} \\
& 2 \mathrm{In}^{3+}+2 \mathrm{Sn}_{\mathrm{Sn}}^{x}+\mathrm{O}_{\mathrm{O}}^{x} \rightarrow 2 \mathrm{In}_{\mathrm{Sn}}+V_{\mathrm{O}}^{00}+\mathrm{Sn}_{\text {surface }}
\end{aligned}
$$

For $1 \%$ and $3 \%$ dopings, if complete doping were to occur, a large amount of oxygen vacancies would be created in the lattice. The thermodynamic solution limit for indium in the $\mathrm{SnO}_{2}$ system has been reported to occur around $3 \% .^{21}$ This lowering of the band gap gives an indication of the stoichiometric deviation (and degeneracy) of the doped $\mathrm{SnO}_{2}$ and the increase in oxygen vacancies within the lattice. It has been

TABLE I. Variation in crystallite size of indium doped $\mathrm{SnO}_{2}( \pm 5 \%$ error).

\begin{tabular}{ccccc}
\hline \hline & \multicolumn{4}{c}{ Crystallite sizes (nm) } \\
\cline { 2 - 5 } $\begin{array}{c}\text { Calcining } \\
\text { temperature }\left({ }^{\circ} \mathrm{C}\right)\end{array}$ & $1 \% \mathrm{In}$ & $3 \%$ In & $6.5 \%$ In & $9 \%$ In \\
\hline 500 & 4 & 4 & 3 & 3 \\
600 & 5 & 5 & 4 & 4 \\
800 & 8 & 8 & 6 & 10 \\
1000 & 13 & 14 & 19 & 23 \\
\hline \hline
\end{tabular}
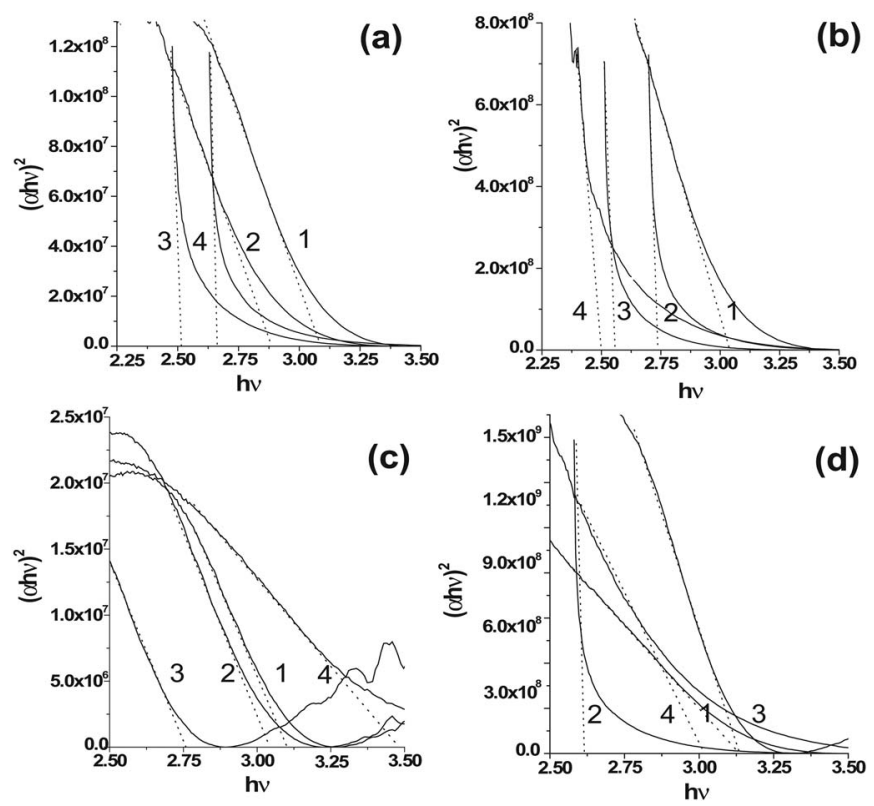

FIG. 2. (a) $1 \% \mathrm{In}-\mathrm{SnO}_{2}$ samples calcined at (1) $500{ }^{\circ} \mathrm{C}, E_{g}=3.1 \mathrm{eV}$, (2) $600{ }^{\circ} \mathrm{C}, E_{g}=2.9 \mathrm{eV}$, (3) $800{ }^{\circ} \mathrm{C}, E_{g}=2.52 \mathrm{eV}$, and (4) $1000{ }^{\circ} \mathrm{C}$, $E_{g}=2.65 \mathrm{eV}$; (b) $3 \% \quad \mathrm{In}-\mathrm{SnO}_{2}$ samples calcined at (1) $500{ }^{\circ} \mathrm{C}$, $E_{g}=3.05 \mathrm{eV}$, (2) $600{ }^{\circ} \mathrm{C}, E_{g}=2.74 \mathrm{eV}$, (3) $800{ }^{\circ} \mathrm{C}, E_{g}=2.55 \mathrm{eV}$, and (4) $1000{ }^{\circ} \mathrm{C}, E_{g}=2.5 \mathrm{eV}$; (c) $6.5 \% \mathrm{In}-\mathrm{SnO}_{2}$ samples calcined at (1) $500{ }^{\circ} \mathrm{C}$, $E_{g}=3.1 \mathrm{eV}$, (2) $600{ }^{\circ} \mathrm{C}, E_{g}=3.04 \mathrm{eV}$, (3) $800{ }^{\circ} \mathrm{C}, E_{g}=2.75 \mathrm{eV}$, and (4) $1000{ }^{\circ} \mathrm{C}, E_{g}=3.43 \mathrm{eV}$; (d) $9 \% \mathrm{In}-\mathrm{SnO}_{2}$ samples calcined at (1) $500{ }^{\circ} \mathrm{C}$, $E_{g}=3.14 \mathrm{eV}$, (2) $600{ }^{\circ} \mathrm{C}, E_{g}=2.62 \mathrm{eV}$, (3) $800{ }^{\circ} \mathrm{C}, E_{g}=3.16 \mathrm{eV}$, and (4) $1000^{\circ} \mathrm{C}, E_{g}=2.95 \mathrm{eV}$

previously shown that at low temperatures (as low as room temperature), a nonequilibrium amount of oxygen vacancies are maintained. ${ }^{22}$ At room temperature, oxygen vacancy concentrations of $10^{23} / \mathrm{m}^{3}$ have been observed.

In order for band bending of the conduction band to occur towards the valence band in a semiconductor, a negative space charge must develop. This usually occurs by an excess of electrons or negative charge. In order to develop this negative charge with excess oxygen vacancies, surface species must adsorb onto the surface of the material and donate electrons. These donated electrons can then associate themselves with positively charged oxygen vacancies. In fact, it has been previously observed by the author's group that the major free carriers in sol-gel derived nanocrystalline $\mathrm{In}-\mathrm{SnO}_{2}$ are, in fact, monoionized oxygen vacancies. ${ }^{22}$ Due to the fact that these nanoparticles are small and comparable in size to their Debye length, the space charge region will completely occupy the material and control the band structure. ${ }^{23}$ At the nanoscale, this surface induced band bending then characterizes the band structure of the material.

Another explanation for the ability of a material to decrease its band gap energy is that the density of surface states induced by chemisorbed oxygen species decreases with decreasing particle size, which would lead to a lesser degree of Fermi pinning. ${ }^{24}$ This would allow the surface barrier to undergo larger changes and control the ability of charged species to move through the material. This decrease in density of surface states is directly caused by the curvature of the nanoparticles. It has been shown using scanning tunneling spectroscopy for nanoparticles (10 and $30 \mathrm{~nm}$ ) that a surface band gap of around $2.5 \mathrm{eV}$ exists. ${ }^{24}$ It is likely that for the $\mathrm{In}-\mathrm{SnO}_{2}$ nanoparticles (sizes ranging from 3 to $23 \mathrm{~nm}$ ), a combination of the decrease in the density of surface states 
and the large amount of oxygen vacancies retained in the material explains the departure in the band gap values from what has been reported. ${ }^{22}$ This also partially explains the enhanced ability for nanocrystalline $\mathrm{In}-\mathrm{SnO}_{2}$ to be used in gas sensor applications at room temperature, since the potential barrier required for charge to move between grains is now reduced with a lower band gap energy. Author's group ${ }^{25}$ has recently shown that In doped $\mathrm{SnO}_{2}$ coated gas sensor at room temperature has a response time of $20 \mathrm{~s}$ for $900 \mathrm{ppm}$ of $\mathrm{H}_{2}$.

The question arises as to why the $6.5 \%$ and $9 \%$ samples exhibited slightly different behaviors than the $1 \%$ and $3 \%$ doped samples. First, both the $6.5 \%$ and $9 \%$ are above the thermodynamically predicted indium doping amount in $\mathrm{SnO}_{2}$ of $3 \%{ }^{21}$ For the $6.5 \% \mathrm{In}-\mathrm{SnO}_{2}$ nanocrystalline samples, it has been shown that using sol-gel techniques and at low calcination temperatures, doping amounts above what is thermodynamically predicted can occur. ${ }^{18}$ From previous Fourier transform infrared studies, it has been demonstrated that, when exposed to $\mathrm{H}_{2}$ gas, the $6.5 \%$ samples do not respond to $\mathrm{H}_{2}$ in the same manner that the $3 \%$ doped samples respond. ${ }^{18}$ In the case of $3 \% \mathrm{In}-\mathrm{SnO}_{2}$, surface species such as $\mathrm{CO}_{2}$ and hydroxyl groups changed with regards to the magnitude of their peaks after exposure to $\mathrm{H}_{2}$. Contrary, the $6.5 \%$ In $-\mathrm{SnO}_{2}$ sample after exposure to hydrogen showed little impact on these surface species. This indicates a difference in the nature of the same adsorbed surface species on the surface of these two different dopings of $\mathrm{SnO}_{2}$. Because of this, surface effects such as band bending and surface density of states would be different, and it would be expected that these two materials would have different electronic behaviors at the nanoscale. This helps us to explain the enhanced gas sensing behavior of $6.5 \%$ In doped $\mathrm{SnO}_{2}$ at low temperatures over other similar material systems. The $6.5 \%$ In doped sample likely has the best trade-off between surface species retained after synthesis and band bending effects.

As gas sensor applications move towards lower working temperatures, knowledge of what can be utilized at the nanoscale becomes very important. The ability to understand the effect of doping and its impact on the surface of nanomaterials is paramount as the surface dominates many features at the nanoscale. For room temperature applications, reduction of the activation energy required for the gas sensing reaction is just as important as the surface reaction. By changing the band gap values, the energy barrier required for species to move through the space charge region can be modified making room temperature applications more of a reality. This can have even wider implications as materials science moves towards better understanding at the nanoscale, fine tuning materials better to specific applications.
For nanocrystalline chemically synthesized In doped $\mathrm{SnO}_{2}$, it has been shown that the optical band gap values for direct transitions are much lower than the expected values reported. The lowest value of the band gap was achieved in the $3 \%$ doped sample calcined at $800^{\circ} \mathrm{C}$, while the highest value of the band gap was achieved in the $6.5 \%$ doped sample calcined at $1000{ }^{\circ} \mathrm{C}$. Because of this reduction in band gap, room temperature gas sensing is possible with a reduction in the potential barrier required for charge movement in nanocrystalline (3\% and $6.5 \%$ doped) $\mathrm{In}-\mathrm{SnO}_{2}$ calcined at $500{ }^{\circ} \mathrm{C}$, when exposed to a reducing gas.

The authors would like to thank NASA-Glenn (FSEC: NAG:32751), ASRC Corporation, NSF-CTS for funding nanotechnology and sensor research, and NSF GK-12 Fellowship.

${ }^{1}$ O. Wurzinger and G. Reinhardt, Sens. Actuators B 103, 104 (2004).

${ }^{2}$ H. Yang, X. Song, X. Zhang, W. Ao, and G. Qiu, Mater. Lett. 57, 3124 (2003).

${ }^{3}$ A. Maciel, P. Lisboa-Filho, E. Leite, C. Paiva-Santos, W. Schreiner, Y. Maniette, and E. Longo, J. Eur. Ceram. Soc. 23, 707 (2003).

${ }^{4}$ H. Yang, S. Han, L. Wang, I. Kim, and Y. Son, Mater. Chem. Phys. 56, 153 (1998).

${ }^{5}$ H. Ahn, H. Choi, K. Park, S. Kim, and Y. Sung, J. Phys. Chem. B 108, 9815 (2004).

${ }^{6}$ G. Xu, Y. Zhang, X. Sun, C. Xu, and C. Yan, J. Phys. Chem. B 109, 3269 (2005).

${ }^{7}$ P. Singh, A. K. Chawla, D. Kaur, and R. Chandra, Mater. Lett. 61, 2050 (2007).

${ }^{8}$ G. Sanon, R. Rup, and A. Mansingh, Phys. Rev. B 44, 11 (1991).

${ }^{9}$ Y. Ma, F. Zhou, L. Lu, and Z. Zhang, Solid State Commun. 130, 313 (2004).

${ }^{10}$ Z. Nabi, A. Kellou, S. Mecabih, A. Khalfi, and N. Benosman, Mater. Sci. Eng., B 98, 104 (2003).

${ }^{11}$ S. Shanthi, C. Subramanian, and P. Ramasamy, Cryst. Res. Technol. 34, 1037 (1999).

${ }^{12}$ A. E. Taverner, C. Rayden, S. Warren, A. Gulino, P. A. Cox, and R. G. Egdell, Phys. Rev. B 51, 11 (1995).

${ }^{13}$ J. Kang, S. Tsunekawa, and A. Kasuya, Appl. Surf. Sci. 174, 306 (2001).

${ }^{14}$ J-H. Chung, Y-S. Choe, and D-S. Kim, Thin Solid Films 349, 126 (1999).

${ }^{15}$ H. Kim and A. Pique, Appl. Phys. Lett. 84, 218 (2004).

${ }^{16}$ S. Shukla, S. Seal, L. Ludwig, and C. Parish, Sens. Actuators B 97, 256 (2004).

${ }^{17}$ S. Shukla, S. Patil, S. C. Kuiry, Z. Rahman, T. Du, L. Ludwig, C. Parish, and S. Seal, Sens. Actuators B 96, 343 (2003).

${ }^{18}$ C. Drake, A. Amalu, J. Bernard, and S. Seal, J. Appl. Phys. 101, 104307 (2007).

${ }^{19}$ J. Robertson, J. Phys. C 12, 4767 (1979).

${ }^{20}$ J. Hays, A. Punnoose, R. Baldner, M. H. Engelhard, J. Peloquin, and K. M. Reddy, Phys. Rev. B 72, 075203 (2005).

${ }^{21}$ F. Sensato, R. Custodio, M. Calatayud, A. Beltran, J. Andres, J. Sambrano, and E. Longo, Surf. Sci. 511, 408 (2002).

${ }^{22}$ C. Drake, S. Deshpande, and S. Seal, Appl. Phys. Lett. 89, 1 (2006).

${ }^{23}$ N. Yamazoe, Sens. Actuators B 5, 7 (1991).

${ }^{24}$ T. G. G. Maffeis, G. T. Owen, C. Malagu, G. Martinelli, M. K. Kennedy, F. E. Kruis, and S. P. Wilks, Surf. Sci. 550, 21 (2004).

${ }^{25}$ S. Deshpande, P. Zhang, N. Posey, J. Cho, and S. Seal, Appl. Phys. Lett. 90, 073118 (2007). 